\title{
Research Collaboration System in Indian Science as Evident from Scientific Database
}

Garvita Jhamb, Meera, K.P Singh

Department of Library \& Information Science

University of Delhi, Delhi

India

\begin{abstract}
In this research we find how the Indian geoscience researchers collaborate and produce science output. The dataset for this analysis the papers indexed in the global database, called as the Web of Science which is used. The dataset is extracted with scientific records for the period of 20 years i.e. 1998-2017. We produce a few indicators which are given as belo. The values of degree of collaboration is 0.90 , the collaboration coefficient is 0.62 , and collaborative index is 3.8 which indicates that the output is emerged as the result of scientific collaboration and research network. We found that the output of the total research, $55.4 \%$ came from national level of collaboration which is followed by the international level at $34.3 \%$. The most prefered nation for collaboration seems to be USA with 56 papers followed by UK with 25 papers in a total of 200 internationally collaborated papers. Interestingly we observed that the internationally collaborated papers get more citations (59.6\%) whereas the natonal contribution is $34.8 \%$. Citation per paper (CPP) for internationally collaborated articles is 22 while that for domestic collaborations is 8 . Overall CPP is 13. Finally we found that the maximum $81.3 \%$ of papers are contained in the top ten journals of which Himalayan Geology occupies the top position. Among them the Journal Geology received highest citation per paper which stands at $C P P=39$.
\end{abstract}

Keywords: Manpower collaboration, Collaborative Research, Scientific Databases

Received: 2 June 2018, Revised 10 July 2018, Accepted 19 July 2018

DOI: $10.6025 / \mathrm{jism} / 2018 / 8 / 4 / 123-134$

(C) 2018 DLINE. All Rights Reserved

\section{Introduction}

Scientometrics is one of the most important measures for the assessment of scientific publications. It is the study of the quantitative as well as qualitative aspects of body of a literature. In this study, we attempted to scientometrically evaluate the literature on Geology published by Indian Geologists. Geology is the study of the Earth, the materials which it is made up of, the structure of those materials, and the processes acting upon those materials. It includes the study of creatures that have inhabited our planet since ages. An important part of geology is the study of how Earth's materials, structures, processes and organisms have changed over time. Geologists work in collaboration to understand the history of our planet for the betterment of future. The better they can understand Earth's history, the better they can foresee how events and processes of the past might influence the future. This paper particularly emphasis on the way the collaboration has been done among the geologists since nowadays collaboration is necessary so as to enhance the visibility of the research at the global level. 


\section{Literature Review}

Azmi (2016) analysed the research productivity of faculty members of the Geology department of Delhi University over a period of 15 years (2001 - 2015) using SCOPUS database. Results show that the research productivity of faculty members is increasing, their publications are getting good citations and their journals have better Impact Factor. Chiu and Ho (2007) studied tsunami related publications seen in the Science Citation Index (SCI). The US and Japan produced 53\% of the total output. English was the dominant language, comprising $95 \%$ of articles. A simulation model was applied to describe the relationship between the number of authors and the number of articles, the number of journals and the number of articles, and the percentage of total articles and the number of times a certain keyword was used. Moreover the tsunami publication patterns in the first 8 months after the Indonesia tsunami occurred on 26 December 2004 indicated a high percentage of non-article publications. Dutta and Nikam (2014) in their research analyzed by the publications indexed in Web of Science on Solar Cell Research for a period of 20 years from 1991-2010 and observed that almost half of the total output emerged out of domestic and international collaboration. Academic institutions had almost equal proportion of output emerging from domestic as well international collaboration. Among the prolific institutions National Physical Laboratory-Delhi of the Council of Scientific and Industrial Research had the highest publications emerging out of collaborative research. At global level, Indian researchers collaborated with 31 countries which had more impact compared to domestic collaboration in terms of citations per paper. Dhoble, Kumar and Shah (2016) analyzed 3,875 records on groundnut from 2000-2013 indexed in CAB abstract from India. It was seen that the relative growth rate is decreasing and hence doubling time is increasing. Maximum publications are a result of collaboration. Also it was observed that Lotka's law is applicable to the research output on groundnut. Elango and Rajendran (2012) examined the authorship trend and collaboration pattern in Marine Sciences literature from the articles indexed in the Indian Journal of Marine Sciences published from 2001 to 2010. The study reveals that the coauthored papers are dominated and the author productivity follows the Lotka's law. Average collaboration rate (0.57) is better collaboration and mean number of authors per joint authored paper is 3.4. It was found that Author productivity follows the Lotka's original distribution. $58 \%$ of the papers are collaborated within the same institution. K, Srinivas, K attained the higher value of dominance factor (0.88). Rajendran, Jeyshankar and Elango (2012) in their study covered the analysis of 506 papers published during 2001- 2010 in the Indian Journal of Marine Sciences using tools such as exponential growth, co-authorship index, publication efficiency index, collaboration index and research length index. Pattern of co-authorship indicates the world average for the multi authors. India is the most producing country to the journal literature. Review articles have attained the higher value of PEI. Sangam, Keshava and Agadi (2009) examined the authorship pattern and collaborative research trends in the field of Marine Engineering based on the data collected from COMPENDEX database from the period 1986 to 2005. It was observed that the average number of authors per paper was increased from 2.16 to 2.68. Also collaborative co-efficient has increased from 0.36 (from 1986 to 1995 ) to 0.491 (from 1996 to 2005). Similarly, the degree of collaboration hiked from 0.63 during 1986-1995 to 0.75 during 1996-2005. Singh (2017) scientometrically

analyzed the 705 publications of Indian journal of Fisheries in terms of collaboration pattern among the scientists for a period of 10 years (2006-2015). Coauthorship was dominant over single authorship. Highest contribution came from the state of Kerala followed by Tamil Nadu. There is a collaboration of 3-4 authors per paper.

\section{Objectives}

The main objectives of the study are:

1. To examine and analyze the authorship pattern of the literature published on Geology from India in the period $1998-2017$.

2. To determine the degree of collaboration, collaboration index, collaboration co-efficient, and co-authorship index.

3. To find out the affinity index of India with the top ten collaborating countries.

4. To examine domestic and international collaboration and its impact in terms of citations per paper.

5. To identify the most preferred sources of publication and calculate the citation impact.

\section{Scope and Methodology}

The required data for the present study has been collected from Web of Science database using the search term "WC= (Geology) AND CU= (India) AND DT= (Articles)" from the period1998-2017. A total of 583 records were retrieved. To fulfil the objectives data was taken for the period of 20 years i.e.1998-2017. Data was analysed and tabulated using MS Excel.

\begin{tabular}{lllllll}
\hline $124 \quad$ Journal of Information \& Systems Management & Volume & 8 & Number & 4 & December & 2018 \\
\hline
\end{tabular}


The following scientometric indicators have been used to analyze the data:

- Degree of collaboration (DC): Degree of Collaboration has been calculated by using the formula as given by Subramanyam (1983)

$$
D C=\frac{N m}{N m+N s}
$$

Where

$D C=$ Degree of Collaboration

$\mathrm{Nm}=$ Number of multi authored contributions

$N s=$ Number of single authored contributions

- Collaboration Index (CI): Collaboration Index has been calculated by using the formula as given by Lawani (1980).

$$
C I=\frac{\sum_{j=1}^{A} j f_{j}}{N}
$$

Where,

$f_{j}$ is the number of $J$ authored papers published in a discipline during a certain period of time $N$ is the total number of research papers published in a discipline during a certain period of time.

- Collaboration Coefficient (CC): The formula for collaboration coefficient (CC) as given by Ajiferuke et al. (1988) is

$$
C C=1-\frac{\sum_{j=1}^{A}(1 / j) f_{i}}{N}
$$

$F_{j}$ denotes the number of $j$ authored research papers; $N$ denotes total number of research papers published; and $k$ is the greatest number of authors per paper. It is observed by Ajiferuke, that $C C$ will indicate zero when a single-authored papers dominate and counted $1-1 / j$ then $j$ authored papers being dominate. This implication shows that higher the value of $C C$, means higher the probability of multi- authored papers.

- Co-authorship Index (CAI): CAI is obtained by calculating proportional output of single, two, multi and mega-authored papers developed Garg and Padhi.

$$
C A I=\frac{N i j / N i o}{N o j / N o o} * 100
$$

\section{Where}

$N i j=$ Number of publications having $\mathrm{j}$ author for a particular block

Nio $==$ Total output for the particular block

$N o j=$ Number of papers having $\mathrm{j}$ authors for all blocks

Noo $=$ Total number of papers for all authors and all blocks

- Affinity Index (AFI): Affinity index is the measure of research collaboration between institutions/countries in a given area of research. It is mathematically expressed as

$$
\mathbf{A F I}=\frac{\text { No. of co-operation links between A and B }}{\text { No. of cooperation links between A and the rest of the institution }} \times 100
$$


- Internationalization Index: Internationalization Index has been calculated using the formula suggested by Frame and Carpenter.

$$
\text { Internationalization Index }=100 \times \frac{\text { Number of international links }}{\text { Total number of papers from the country }}
$$

\section{- Domestic Collaborative Index (DCI)}

$$
D C I=\frac{D i / D i o}{D o / D o o} * 100
$$

Where $D i=$ number of domestically co-authored papers for block $i$;

Dio $=$ total output of block $i$

$D o=$ total number of domestically co-authored papers

Doo $=$ total output

- International Collaborative Index (ICI): It is the proportional output of internationally co-authored papers and is an improvement over internationalization index suggested by Nagpaul.

$$
I C I=\frac{I i / I i o}{I o / I o o} * 100
$$

Where $I i=$ number of internationally co-authored papers for block $i$

Iio $=$ total output of block $i$

$I o=$ number of internationally co-authored papers for all the blocks

Ioo $=$ total output

\begin{tabular}{|c|c|c|c|c|c|c|c|c|c|c|c|c|c|c|c|}
\hline \multirow{2}{*}{ Block Year } & \multicolumn{14}{|c|}{ No. of Authors } & \multirow{2}{*}{$\begin{array}{c}\text { Total } \\
\text { Articles }\end{array}$} \\
\hline & 1 & 2 & 3 & 4 & 5 & 6 & 7 & 8 & 9 & 10 & 11 & 13 & 15 & 16 & \\
\hline 1998-2002 & 15 & 16 & 20 & 18 & 2 & 3 & 2 & 1 & 1 & 0 & 0 & 0 & 0 & 0 & 78 \\
\hline $2003-2007$ & 13 & 23 & 23 & 21 & 7 & 3 & 2 & 2 & 0 & 0 & 0 & 0 & 0 & 0 & 94 \\
\hline 2008-2012 & 16 & 35 & 55 & 41 & 17 & 6 & 4 & 3 & 1 & 1 & 0 & 0 & 0 & 1 & 180 \\
\hline 2013-2017 & 16 & 41 & 63 & 44 & 26 & 16 & 9 & 9 & 2 & 0 & 1 & 3 & 1 & 0 & 231 \\
\hline $\begin{array}{c}\text { Total } \\
\text { Articles }\end{array}$ & 60 & 115 & 161 & 124 & 52 & 28 & 17 & 15 & 4 & 1 & 1 & 3 & 1 & 1 & 583 \\
\hline
\end{tabular}

\section{Data Analysis}

\section{Authorship Pattern}

Table 1. Authorship Pattern

Table 1 provides the authorship pattern for the four block periods of 5 years each. The number of authors range from 1 to 16 . Most of the articles have been produced by multiple authors. Total 523 (89.7\%) publications were published in co-authorship whereas only $60(10.3 \%)$ in single authorship. In multiple-authorship, highest number of publications (161) is a result of collaboration between three authors followed by four authors (124) and the collaboration has gone up to 16 authors having one publication in the year block 2008-2012. Also there is one publication having 15 authors, three publications having 13 authors and one publication having 10 and 11 authors each. The total numbers of publications have been increasing in each block period. Number of articles in the recent decade increased by more than twice (411) as compared to the first decade (172).

126 Journal of Information \& Systems Management Volume 8 Number 4 December 2018




\begin{tabular}{|c|c|c|c|c|c|r|}
\hline Block Years & $\begin{array}{c}\text { Single-Authored } \\
\text { Paper }\end{array}$ & $\begin{array}{c}\text { Multi-Authored } \\
\text { Paper }\end{array}$ & Total & DC & CC & $C I$ \\
\hline $\mathbf{1 9 9 8 - 2 0 0 2}$ & 15 & 63 & 78 & 0.81 & 0.54 & 3.5 \\
\hline $\mathbf{2 0 0 3 - 2 0 0 7}$ & 13 & 81 & 94 & 0.86 & 0.58 & 3.5 \\
\hline $\mathbf{2 0 0 8 - 2 0 1 2}$ & 16 & 164 & 180 & 0.91 & 0.62 & 3.7 \\
\hline $\mathbf{2 0 1 3 - 2 0 1 7}$ & 16 & 215 & 231 & 0.93 & 0.66 & 4.1 \\
\hline Total & $\mathbf{6 0}$ & $\mathbf{5 2 3}$ & $\mathbf{5 8 3}$ & $\mathbf{0 . 9 0}^{*}$ & $\mathbf{0 . 6 2} *$ & $\mathbf{3 . 8}^{*}$ \\
\hline
\end{tabular}

(*indicate the average values. $\mathrm{DC}=$ Degree of collaboration, $\mathrm{CC}=$ Collaboration Coefficient, $\mathrm{CI}=$ Collaboration Index $)$

Table 2. Collaborative Indicators

Table 2 indicates the values of various collaborative measures including degree of collaboration, collaborative index, and collaboration coefficient for each block year. It can be observed that degree of collaboration has increased consistently over the period with maximum being in the block 2013-2017 (0.93). Overall its value is 0.90 which shows authors tendency to work in collaboration rather isolation. Correspondingly, Collaboration coefficient also increased over the years with maximum being 0.66 in the block 2013-2017. Overall value is 0.62 which indicates that collaboration is mainly characterized by coauthored papers and not by single authored papers. The values of degree of collaboration and collaboration co-efficient thus support each other.

Collaboration index is the measure of number of multi-authors per multi-authored papers. Here, we can see that average value of $\mathrm{CI}$ is 3.8 which mean that on an average 3-4 authors have worked together towards a single paper. Figure 1 shows the degree of collaboration and collaboration co-efficient over the period of study.

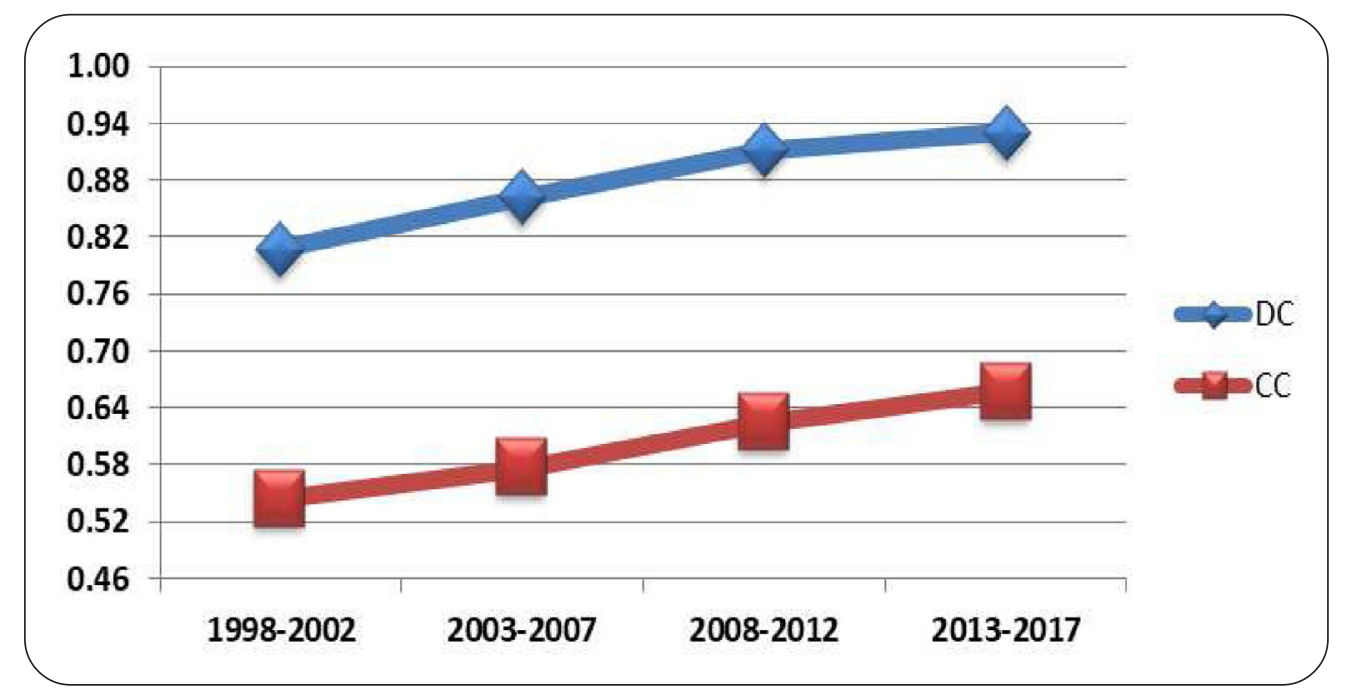

Figure 1. Degree of Collaboration and Collaboration Coefficient

Table 3 indicates the calculated values of Co-authorship Index (CAI) for publications having single author, two-authors, three authors, four authors and more than four authors. CAI measures the tendency of co-authorship and was proposed by Garg and Padhi. It is measured by the formula mentioned in the methodology numbered ' $\mathrm{d}$ '. CAI $=100$ indicates that the coauthorship effort for a particular type of authorship corresponds to the overall average, CAI $>100$ reflects higher than average coauthorship effort and CAI $<100$ shows lower than average co-authorship effort for a given type of authorship pattern.

From table 3 we can observe that the value of CAI for single authors have decreased from 187 to 67 , which means there is a substantial decrease in the single authorship with respect to overall output. In case of double authorship, CAI has increased from 43 to 309 . For three coauthors, it was above average only in the 2008-2012 block with slightly less than average value during 2013-2017. In case of four authorship, it was above average for all the blocks except 2013-2017 in which its value fall down to less 


\begin{tabular}{|c|c|c|c|c|c|c|c|c|c|c|c|}
\hline $\begin{array}{c}\text { Block } \\
\text { Years }\end{array}$ & $\begin{array}{c}\text { Single } \\
\text { Authors }\end{array}$ & CAI & $\begin{array}{c}\text { Two } \\
\text { Authors }\end{array}$ & CAI & $\begin{array}{c}\text { Three } \\
\text { Authors }\end{array}$ & CAI & $\begin{array}{c}\text { Four } \\
\text { Authors }\end{array}$ & CAI & $\begin{array}{c}\text { Mega } \\
\text { Authored } \\
\text { Papers }\end{array}$ & CAI & $\begin{array}{c}\text { Total } \\
\text { Papers }\end{array}$ \\
\hline $\begin{array}{c}\mathbf{1 9 9 8}- \\
\mathbf{2 0 0 2}\end{array}$ & 15 & $\mathbf{1 8 7}$ & 16 & $\mathbf{4 3}$ & 20 & $\mathbf{9 3}$ & 18 & $\mathbf{1 0 9}$ & 9 & $\mathbf{5 5}$ & $\mathbf{7 8}$ \\
\hline $\begin{array}{c}\mathbf{2 0 0 3 -} \\
\mathbf{2 0 0 7}\end{array}$ & 13 & $\mathbf{1 3 4}$ & 23 & $\mathbf{8 7}$ & 23 & $\mathbf{8 9}$ & 21 & $\mathbf{1 0 5}$ & 14 & $\mathbf{7 1}$ & $\mathbf{9 4}$ \\
\hline $\begin{array}{c}\mathbf{2 0 0 8}- \\
\mathbf{2 0 1 2}\end{array}$ & 16 & $\mathbf{8 6}$ & 35 & $\mathbf{2 0 5}$ & 55 & $\mathbf{1 1 1}$ & 41 & $\mathbf{1 0 7}$ & 33 & $\mathbf{8 7}$ & $\mathbf{1 8 0}$ \\
\hline $\begin{array}{c}\mathbf{2 0 1 3}- \\
\mathbf{2 0 1 7}\end{array}$ & 16 & $\mathbf{6 7}$ & 41 & $\mathbf{3 0 9}$ & 63 & $\mathbf{9 9}$ & 44 & $\mathbf{9 0}$ & 67 & $\mathbf{1 3 7}$ & $\mathbf{2 3 1}$ \\
\hline $\begin{array}{c}\text { Total } \\
\text { Papers }\end{array}$ & $\mathbf{6 0}$ & & $\mathbf{1 1 5}$ & & $\mathbf{1 6 1}$ & & $\mathbf{1 2 4}$ & & $\mathbf{1 2 3}$ & & $\mathbf{5 8 3}$ \\
\hline
\end{tabular}

(Mega Authored: Papers with 5 or more authors)

Table 3. Co-authorship Index (CAI)

than the average. For more than 4 authors working in collaboration, value is more than average only during last 5 years. Highest collaborative effort has been observed among the two authors (309).

Overall, for all the multi-authored papers, we can say that, trend in co-authorship effort has increased and become more than the average in the last two block years 2008-2012 (102) and 2013-2017 (104).

\section{Top Collaborating Countries and Affinity Index}

\begin{tabular}{|l|c|c|c|c|c|c|c|c|c|c|c|c|}
\hline $\begin{array}{l}\text { Block } \\
\text { Years }\end{array}$ & USA & UK & $\begin{array}{c}\text { Germ } \\
\text {-any }\end{array}$ & $\begin{array}{c}\text { Jap } \\
-a n\end{array}$ & $\begin{array}{c}\text { Austra- } \\
\text { lia }\end{array}$ & $\begin{array}{c}\text { Chi } \\
n a\end{array}$ & Brazil & $\begin{array}{c}\text { South } \\
\text { Africa }\end{array}$ & $\begin{array}{c}\text { Fran- } \\
\text { ce }\end{array}$ & $\begin{array}{c}\text { Mexi } \\
\text { co }\end{array}$ & $\begin{array}{c}\text { Rest } \\
\text { Natio } \\
n s\end{array}$ & $\begin{array}{c}\text { Total } \\
\text { Links }\end{array}$ \\
\hline $\begin{array}{l}\mathbf{1 9 9 8} \\
\mathbf{2 0 0 2}\end{array}$ & 11 & 8 & 4 & 3 & 2 & 1 & 4 & 1 & 2 & 0 & 2 & 38 \\
\hline $\begin{array}{l}\mathbf{2 0 0 3 -} \\
\mathbf{2 0 0 7}\end{array}$ & 17 & 3 & 6 & 4 & 2 & 0 & 2 & 2 & 3 & 5 & 10 & 54 \\
\hline $\begin{array}{l}\mathbf{2 0 0 8}- \\
\mathbf{2 0 1 2}\end{array}$ & 11 & 7 & 4 & 11 & 3 & 4 & 3 & 5 & 1 & 3 & 21 & 73 \\
\hline $\begin{array}{l}\mathbf{2 0 1 3}- \\
\mathbf{2 0 1 7}\end{array}$ & 17 & 7 & 10 & 4 & 13 & 14 & 4 & 5 & 5 & 1 & 32 & 112 \\
\hline $\begin{array}{l}\text { Total } \\
\text { Links }\end{array}$ & $\mathbf{5 6}$ & $\mathbf{2 5}$ & $\mathbf{2 4}$ & $\mathbf{2 2}$ & $\mathbf{2 0}$ & $\mathbf{1 9}$ & $\mathbf{1 3}$ & $\mathbf{1 3}$ & $\mathbf{1 1}$ & $\mathbf{9}$ & $\mathbf{6 5}$ & $\mathbf{2 7 7}$ \\
\hline
\end{tabular}

Table 4. Top Collaborating Countries

Out of the 583 publications, 200 papers (34.3\%) were published in collaboration with 42 countries of the world. These 200 articles contain 277 links from 42 countries. One link is counted even if a country appears more than one times in a single article. Top 10 nations contribute maximum links (76.5\%) while rest of the 32 countries appears 65 times. Table 4 represents the block year-wise number of articles of India with the top 10 collaborating countries. The highest number of collaboration was with USA with 56 papers (28\%) followed by UK with 25 papers (12.5\%). It can be observed for the table that there is an increase in collaboration pattern with Germany, Australia and China. Figure 2 represents the collaboration network.

Table 5 indicates the affinity index value of India with the top 10 collaborating countries. The highest value of AFI was seen in the block year 2003-2007 (31) with USA. There was no collaboration between India and Mexico in the first block year and between India and China in the second block year. The highest overall AFI value is 20 with USA however with the increase in

128 Journal of Information \& Systems Management Volume 8 Number 4 December 2018




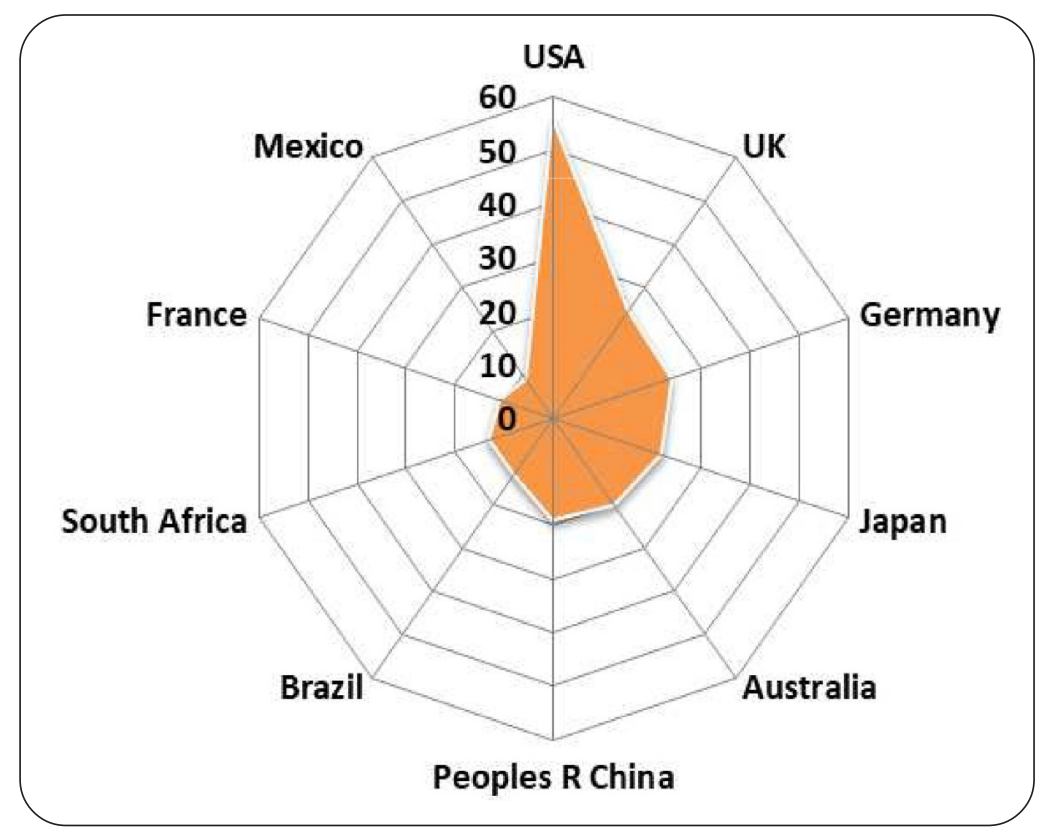

Figure 2. Top 10 Collaborating Countries

Affinity Index

\begin{tabular}{|l|c|c|c|c|c|c|c|c|c|c|}
\hline $\begin{array}{l}\text { Block } \\
\text { Years }\end{array}$ & USA & UK & Germany & Japan & Australia & China & Brazil & $\begin{array}{l}\text { South } \\
\text { Africa }\end{array}$ & France & Mexico \\
\hline $\mathbf{1 9 9 8 - 2 0 0 2}$ & 29 & 21 & 11 & 8 & 5 & 3 & 11 & 3 & 5 & 0 \\
\hline $\mathbf{2 0 0 3 - 2 0 0 7}$ & 31 & 6 & 11 & 7 & 4 & 0 & 4 & 4 & 6 & 9 \\
\hline $\mathbf{2 0 0 8 - 2 0 1 2}$ & 15 & 10 & 5 & 15 & 4 & 5 & 4 & 7 & 1 & 4 \\
\hline $\mathbf{2 0 1 3 - 2 0 1 7}$ & 15 & 6 & 9 & 4 & 12 & 13 & 4 & 4 & 4 & 1 \\
\hline Overall & $\mathbf{2 0}$ & $\mathbf{9}$ & $\mathbf{9}$ & $\mathbf{8}$ & $\mathbf{7}$ & $\mathbf{7}$ & $\mathbf{5}$ & $\mathbf{5}$ & $\mathbf{4}$ & $\mathbf{3}$ \\
\hline
\end{tabular}

Table 5. Affinity Index

number of collaborative papers; the year wise AFI with USA displays a decreasing trend.

AFI value $>1.0=$ more production in collaboration, while $<1=$ reverse. All the values during the period of study were $>1$ which shows that there exist positive affinity between India and the top 10 nations.

\section{Internationalization Index}

The above table clearly indicates that there has been positive affinity between India and the top 10 countries of collaboration. To depict this more markedly, internationalization index is calculated using the formula suggested by Frame and Carpenter as mentioned in the methodology. By calculating it for the present study as follows we see that II is 138.5,

$$
\text { Internationalization Index }=100 \times \frac{277}{200}=138.5
$$

Therefore, the internationalization index of geology literature by Indian authors is 138.5 


\section{Nature of Collaboration}

\begin{tabular}{|c|c|c|c|c|}
\hline Block Years & $N C$ & $D C(D C I)$ & $I C(I C I)$ & Total Papers \\
\hline $1998-2002$ & 15 & $31(72)$ & $32(120)$ & 78 \\
\hline $2003-2007$ & 13 & $40(77)$ & $41(127)$ & 94 \\
\hline $\mathbf{1 9 9 8 - 2 0 0 7}$ & $\mathbf{2 8}$ & $\mathbf{7 1 ( 7 5 )}$ & $\mathbf{7 3}(\mathbf{1 2 4})$ & $\mathbf{1 7 2}$ \\
\hline $2008-2012$ & 16 & $109(109)$ & $55(89)$ & 180 \\
\hline $2013-2017$ & 16 & $143(112)$ & $72(91)$ & 231 \\
\hline $\mathbf{2 0 0 8 - 2 0 1 7}$ & $\mathbf{3 2}$ & $\mathbf{2 5 2 ( 1 1 1 )}$ & $\mathbf{1 2 7}(\mathbf{9 0})$ & $\mathbf{4 1 1}$ \\
\hline Total & $\mathbf{6 0}$ & $\mathbf{3 2 3}$ & $\mathbf{2 0 0}$ & $\mathbf{5 8 3}$ \\
\hline
\end{tabular}

(Note: $\mathrm{NC}=$ No Collaboration, $\mathrm{DC}=$ Domestic Collaboration, $\mathrm{DCI}=$ Domestic Collaboration Index, IC = International Collaboration, ICI= International Collaboration Index)

Table 6. Distribution of output according to nature of collaboration

An analysis of the collaborative papers was also made according to the nature of collaboration: as domestic and international as well as no collaboration. Out of these 583 articles, $55.4 \%$ are domestically collaborated and $34.3 \%$ are collaborated at global level. While rest of the articles (10.3\%) have no collaboration at all. It is clear that the number of papers written in domestic collaboration is much more as compared to papers written in international collaboration. Over the period of 20 years, single authored publications have remained consistent. Domestic collaborations have increased almost three folds in the later decade while international collaborations have increased almost 1.5 times.

In table 6 the values domestic collaboration index (DCI) and international collaboration index (ICI) is calculated using the formulas mentioned in the methodology. The values of DCI or ICI $=100$ indicates the country's collaborative effort is equal with respect to the world average. DCI or ICI $>100$ indicates collaboration is higher than the world average and DCI or ICI $<100$ reflects less than average collaboration. From table 6 we can infer that in case of domestic collaborations the value of DCI has increased from 75 in first decade to 111 in later decade. That means domestic collaborations have gone above average with respect to world. In case of international collaborations, though the output has increased in every block-year the value of ICI has reached below world's average because number of papers in contrast to domestic collaborations is less. The value of ICI was above average in first decade (124) which went down to below average (90) in the later decade. Figure 3 represents the block year-wise output with respect to nature of collaborations.

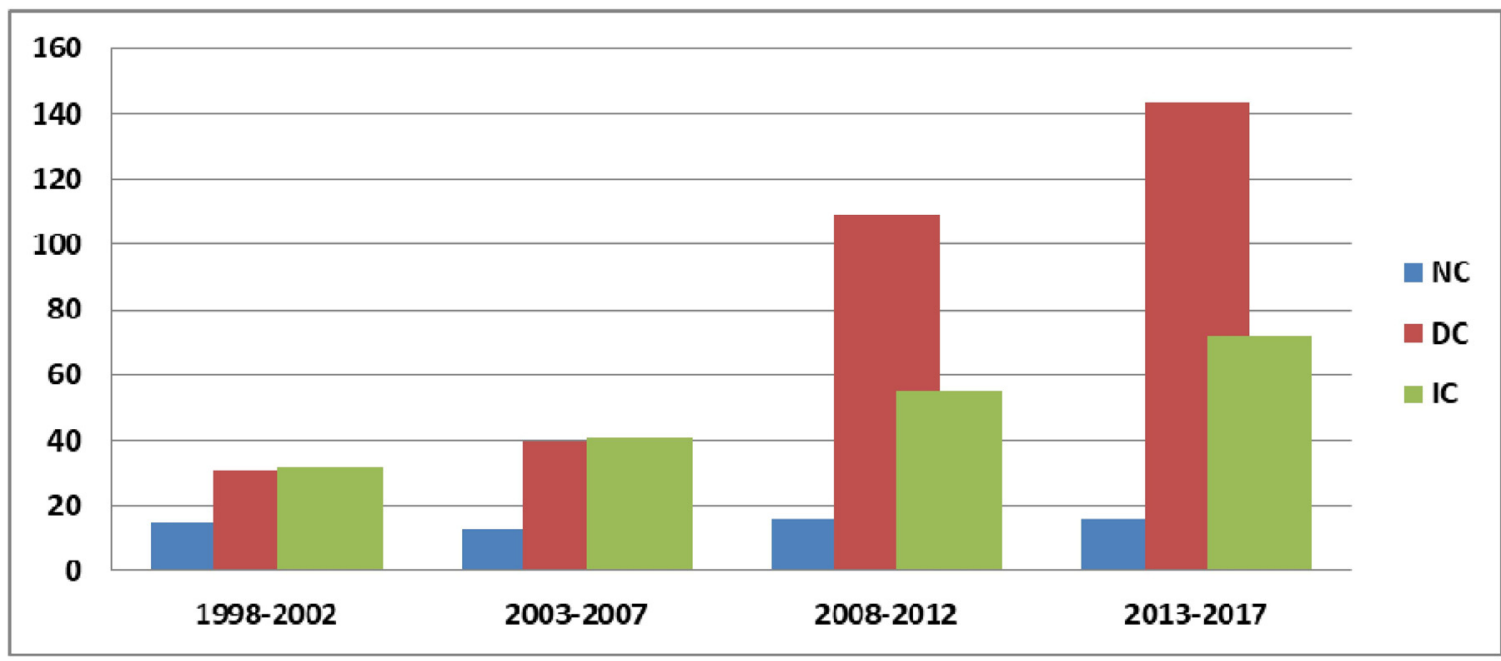

(Note: $\mathrm{NC}=$ No Collaboration, $\mathrm{DC}=$ Domestic Collaboration, $\mathrm{IC}=$ International Collaboration)

Figure 3. Block year-wise distribution of single authored papers, domestic and international collaborations

130 Journal of Information \& Systems Management Volume 8 Number 4 December 2018




\section{Impact of Collaboration}

\begin{tabular}{|c|c|c|c|c|c|c|c|c|}
\hline \multirow{2}{*}{$\begin{array}{c}\text { Citation } \\
\text { Count }\end{array}$} & \multicolumn{2}{|c|}{$\begin{array}{l}\text { Single } \\
\text { Authored }\end{array}$} & \multicolumn{2}{|c|}{$\begin{array}{c}\text { Domestic } \\
\text { Collaborations }\end{array}$} & \multicolumn{2}{|c|}{$\begin{array}{c}\text { International } \\
\text { Collaborations }\end{array}$} & \multicolumn{2}{|c|}{ Overall } \\
\hline & TP & $\mathrm{TC}$ & TP & TC & TP & TC & TP & TC \\
\hline 0 & 16 & 0 & 64 & 0 & 13 & 0 & 93 & 0 \\
\hline 1 & 9 & 9 & 48 & 48 & 14 & 14 & 71 & 71 \\
\hline 2 & 3 & 6 & 38 & 76 & 9 & 18 & 50 & 100 \\
\hline 3 & 3 & 9 & 16 & 48 & 11 & 33 & 30 & 90 \\
\hline 4 & 2 & 8 & 19 & 76 & 11 & 44 & 32 & 128 \\
\hline 5 & 1 & 5 & 15 & 75 & 8 & 40 & 24 & 120 \\
\hline 6 to 20 & 22 & 264 & 88 & 873 & 75 & 878 & 185 & 2015 \\
\hline 21 to 40 & 4 & 112 & 21 & 557 & 23 & 671 & 48 & 1340 \\
\hline 41 to 60 & 0 & 0 & 8 & 400 & 18 & 903 & 26 & 1303 \\
\hline 61 to 80 & 0 & 0 & 6 & 422 & 5 & 348 & 11 & 770 \\
\hline 81 to 100 & 0 & 0 & 0 & 0 & 7 & 630 & 7 & 630 \\
\hline$>100$ & 0 & 0 & 0 & 0 & 6 & 833 & 6 & 833 \\
\hline Total & 60 & 413 & 323 & 2575 & 200 & 4412 & 583 & 7400 \\
\hline CPP & & 7 & & 8 & & 22 & & 13 \\
\hline
\end{tabular}

(Note: $\mathrm{TP}=$ Total Papers, $\mathrm{TC}=$ Total Citations)

Table 7. Citation Count

Citation count measures the impact of each article by counting the number of times it has been cited by other articles. More citations refer to more visibility, impact and influence. Table 7 shows the citation pattern of 583 articles. A total of 7400 citations were received by 583 publications having average rate of citation per paper as 13 . Maximum citations $(59.6 \%)$ have been received by the articles written in international collaboration. Domestically collaborated articles received $34.8 \%$ citations. Citation per paper is more for international collaboration (22) as compared to domestic collaboration with $\mathrm{CPP}=8$. In terms of uncitedness, $19.8 \%$ of domestically collaborated papers remained uncited, while only $6.5 \%$ has got no citations in case of internationally collaborated papers.

From the above table, we can see that only 6 articles roughly $1 \%$ have received more than 100 citations. These 6 articles are the result of international collaborations. On the contrary there are 93 articles (16\%) which have received no citations at all. Maximum articles 207(35.5\%) have received citations in the range 1 to 5 followed by 185 articles (31.7\%) receiving citations in the range 6 to 20 .

Maximum proportion of citations (903) in case of international collaborations has been received in the range of 41-60 by 18 articles followed by 75 articles which received 878 citations in the range of 6-20. Domestic and single authored publications have got maximum citations in the range of 6-20. This shows that collaboration at global level help in increasing the visibility as well as impact of research. Figure 4 displays the contrast between domestic and international collaborations in terms of citation per paper and the percentage of papers which remained uncited.

Total research output of 583 articles has been scattered in 39 journals. Table 3 mentions the top 10 sources of publications chosen by the geologists to publish their research. These ten sources consists $81.3 \%$ of the total output while rest of the output $(18.7 \%)$ is distributed among 29 journals. Himalayan Geology, published by Wadia Institute of Himalayan Geology, India contains the maximum number of articles followed by Sedimentary Geology, published by Elsevier BV, Netherlands having impact factors as 0.410 and 2.575 respectively.

$80.7 \%$ of the total citations are received by the articles published in the above top 10 journals. Geology, product of Geological Society of America consisting fourth highest number of publications (38) have received highest number of citations (1496) 


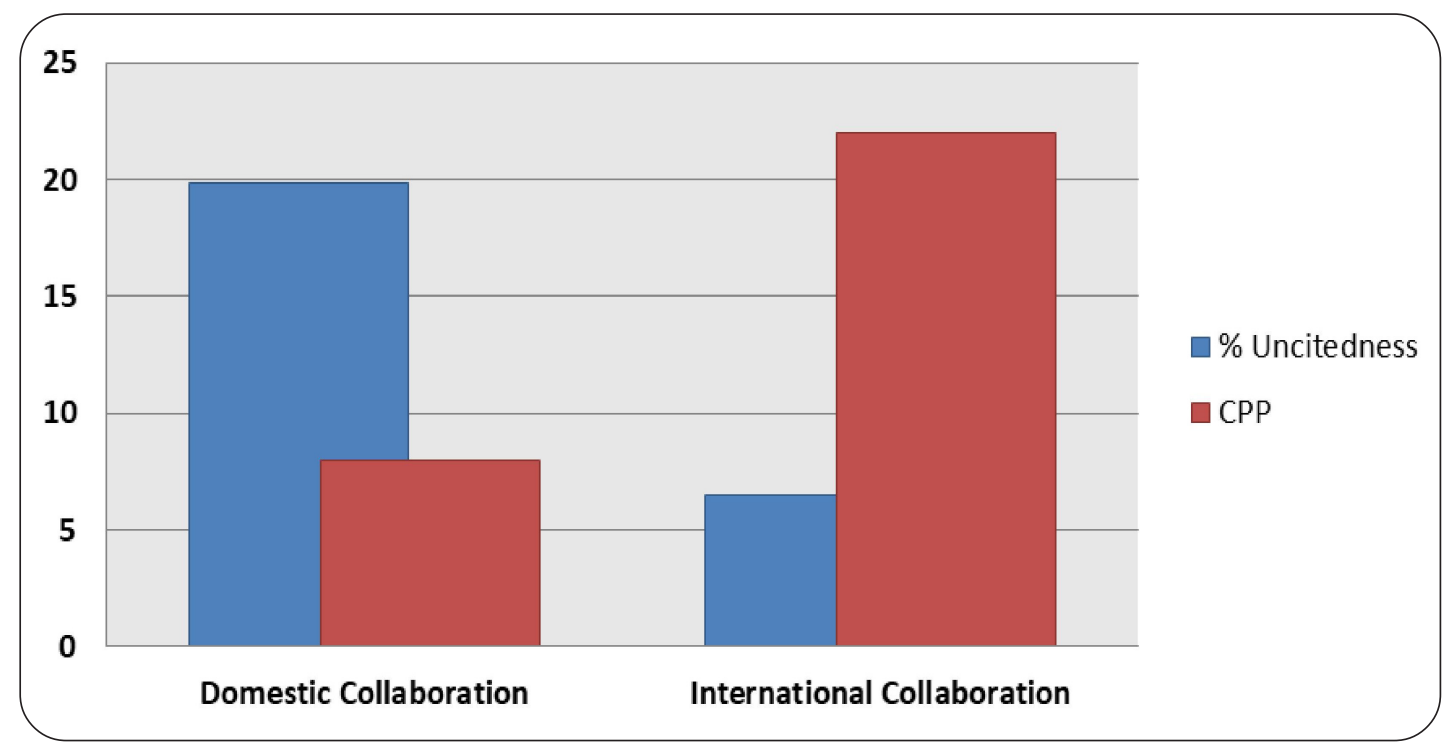

Figure 4. Citations per Paper (CPP) and Uncitedness vs nature of collaboration

\begin{tabular}{|c|l|c|c|c|c|c|}
\hline No. & \multicolumn{1}{|c|}{ Journal Name } & $\begin{array}{c}\text { Impact } \\
\text { Factor }\end{array}$ & $\begin{array}{c}\text { Publication } \\
\text { Country }\end{array}$ & $\begin{array}{c}\text { Number } \\
\text { of } \\
\text { Articles }\end{array}$ & $\begin{array}{c}\text { Number } \\
\text { of } \\
\text { Citations }\end{array}$ & CPP \\
\hline J1 & Himalayan Geology & 0.410 & India & 175 & 470 & 3 \\
\hline J2 & Sedimentary Geology & 2.575 & Netherlands & 64 & 1428 & $\mathbf{2 2}$ \\
\hline J3 & International Geology Review & 2.875 & Philadelphia & 41 & 544 & 13 \\
\hline J4 & Geology & 4.635 & USA & 38 & 1496 & $\mathbf{3 9}$ \\
\hline J5 & Journal Of Geology & 2.015 & Chicago & 36 & 912 & $\mathbf{2 5}$ \\
\hline J6 & Ore Geology Reviews & 3.993 & Amsterdam & 35 & 144 & 4 \\
\hline J7 & Cretaceous Research & 1.928 & London & 27 & 308 & 11 \\
\hline J8 & Carbonates And Evaporites & 0.947 & New York & 20 & 86 & 4 \\
\hline J9 & Resource Geology & 1.259 & USA & 19 & 67 & 4 \\
\hline J10 & $\begin{array}{l}\text { Journal Of Metamorphic } \\
\text { Geology }\end{array}$ & 4.418 & USA & 19 & 522 & $\mathbf{2 7}$ \\
\hline J39 & Other 29 Journals & - & - & 109 & 1423 & 13 \\
\hline & \multicolumn{2}{|c|}{ Total } & - & $\mathbf{5 8 3}$ & $\mathbf{7 4 0 0}$ & $\mathbf{1 3}$ \\
\hline
\end{tabular}

Table 8. Preferred Journals

followed by Sedimentary Geology with its 64 publications having received 1428 citations.

In terms of Citation per paper (CPP), Geology has got the highest CPP (39) followed by Journal of Metamorphic Geology having 27 citations on an average to its 19 articles. Also the Journal of Geology has an average 25 citations to its 36 articles. It can be seen that the journal of high impact factor receives highest citations.

\section{Findings}

1. There has been collaboration of up to 16 authors in the field of geology. Maximum output has been produced by the collaboration of 3-4 authors.

\begin{tabular}{lllllll}
\hline $132 \quad$ Journal of Information \& Systems Management & Volume & 8 & Number & 4 & December 2018 \\
\hline
\end{tabular}




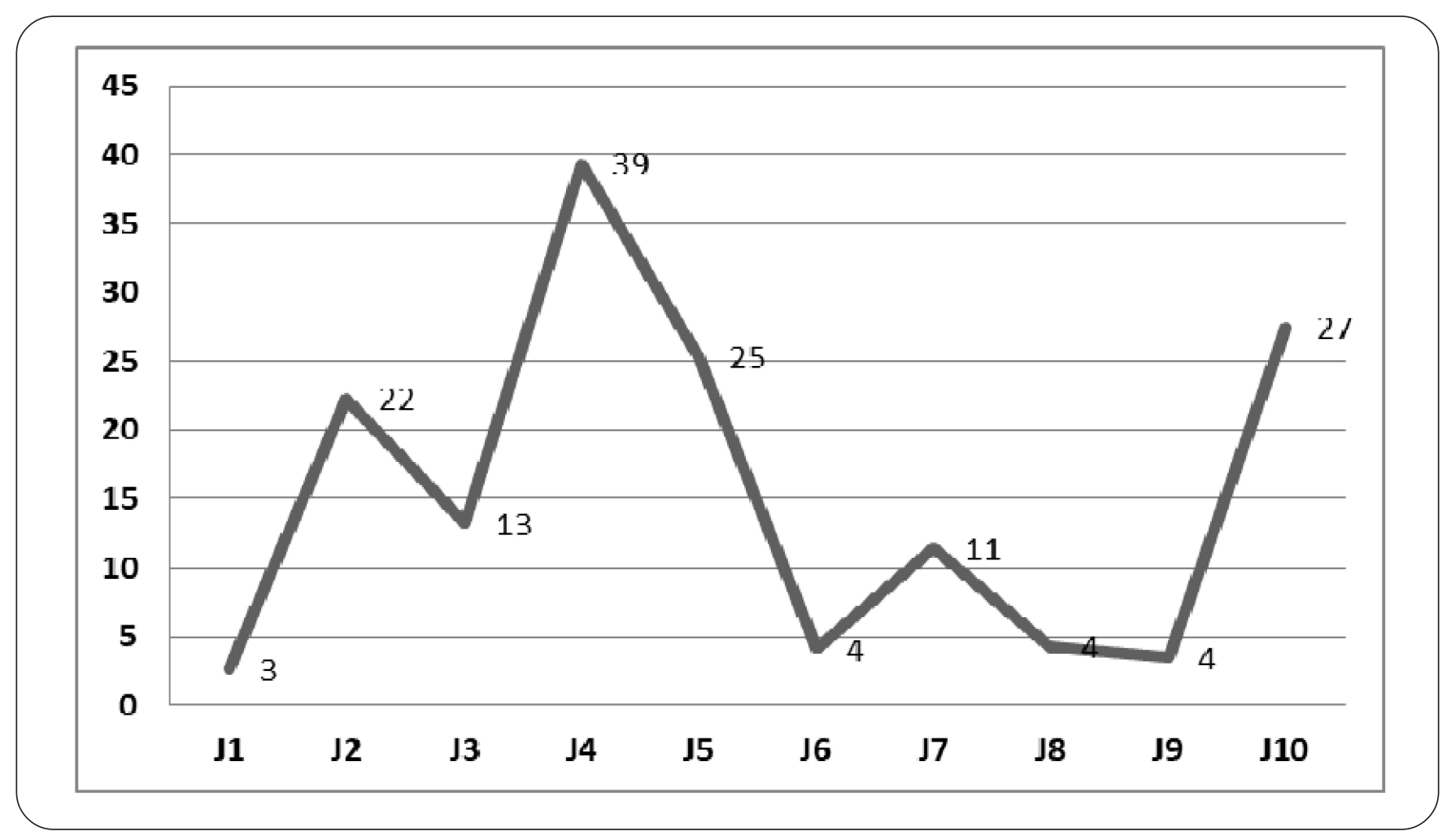

Figure 5. Citation per Paper (CPP) of top 10 journals

2. Overall value of degree of collaboration is 0.90 and that of collaboration co-efficient is 0.62 . 3. Trend in co-authorship increased and became more than the average for three authors and mega authors in the last five year period (2012-2017).

4. Out of the 583 articles, 200 papers (34.3\%) were published in collaboration with 42 countries, highest with USA (28\%) followed by UK $(12.5 \%)$.

5. The maximum affinity of India with USA was seen in the block year 2003-2007(AFI=31).

6. Maximum articles (55.4\%) are a result of domestic collaboration while $34.3 \%$ are collaborated at global level. $10.3 \%$ articles has no collaboration at all.

7. Domestic collaborations have gone above average ( $\mathrm{DCI}=111)$ while international collaborations reached below world's average (ICI=90) in the recent decade (2008-2017).

8. A total of 7400 citations were received by 583 articles having average rate of citation per paper as 13 . Only $1 \%$ articles have received more than 100 citations while

9. Citation per paper (CPP) for internationally collaborated articles is 22 while that for domestic collaborations is 8 .

$10.16 \%$ of the total output has received no citations. Domestically collaborated papers contribute to the major proportion $(19.8 \%)$ of uncited papers as compared to internationally collaborated papers $(6.5 \%)$.

11. Maximum proportion of citations in case of internationally collaborated articles has been received in the range of 41-60. Domestic and single authored publications have got citations in the range of 6-20.

12. Total research output has been scattered in 39 journals out of which ten sources consists $81.3 \%$ of the total output while rest of the output (18.7\%) is distributed among 29 journals.

13. Himalayan Geology $(\mathrm{IF}=0.410)$, published by Wadia Institute of Himalayan Geology, India contains the maximum number of articles (30.1\%).

14. Articles which got published in the journal Geology received the highest number of citations $(20.2 \%)$ with CPP=39. 


\section{Conclusion}

From the study we can conclude that the Indian geologists have preferred to work in groups rather individually. Increase in the trend in co-authorship can be seen from the consistently increasing values of degree of collaboration and co-authorship index. However, in terms of number domestic collaborations have dominated international collaborations; the impact of internationally collaborated papers is more than that of domestic one. The proportion of papers remaining uncited is more in case of domestic as well as single authored publications while international collaborations have got on an average 22 citations per paper. Overall, 13 citations have been received by 583 articles published in the field of Geology. Maximum articles have got citations ranging from 6 to 20. Also, articles which are published in the journal Geology have received maximum citations. We can say that the nature of collaboration as well as nature of publishing journal clearly influences the impact of research publications.

\section{References}

[1] https://geology.com/articles/what-is-geology.shtml

[2] Azmi, Islam., Nazrul. (2016). Bibliometric Analysis of Research Publications of Geology Department, Delhi University, India, 2001-2015. SSARSC International Journal of Library, Information Networks and Knowledge, 1 (2) 1-12.

[3] Chiu,Wen-Ta, Ho, Yuh-Shan. (2007). Bibliometric Analysis of Tsunami Research. Scientometrics, 73 (1) 3-17.

[4] Dutta, Bharvi., Nikam, Khaiser. (2014). Scientometrics of collaboration pattern in solar cell research in India. Annals of Library and Information Studies, 61, 65-73.

[5] Dhoble, Shilpa., Kumar, Sudhir., Shah, Leena. (2015). Collaboration Pttern in Groundnut (Oilseed) Research in India in 21st Century: A Bibliometric Study. 11th International Conference on Webometrics, Informetrics, and Scientometrics (WIS) and the 16th COLLNET Meeting 2015, New Delhi. (p. 304-313)

[6] Elango, B., Rajendran, P. (2012). Authorship trends and collaboration pattern in the marine Marine Engineering: A Bibliometric Study. JLIS, 34 (2) 119-123.

[7] Garg, K. C., Padhi, P. (2001). A study of collaboration in science and technology. Scientometrics, 51 (2) 415-427.

[8] Rajendran, P., Jeyshankar, R., Elango, B. (2012). Research Trends In Indian Journal Of Marine Sciences (2001- 2010): A Scientometric Study. International Journal of Digital Library Services, 2 (4) 42-50.

[9] Sangam, S. L., Keshava, Agadi, K. B. (2009). Collaborative Research Trends in the Field ofsciences literature: a scientometric study. International Journal of Information Dissemination and Technology, 2 (3) 166-169.

[10] Singh, Pratap, Mahendra. (2017). Scientometrics Analysis of Collaborative Patterns in Indian Journal of Fisheries. Trends in Bibliometrics and Scientometrics Studies. 12th International Conference on Webometrics, Informetrics, and Scientometrics (WIS) and the 17th COLLNET Meeting 2016, France. p. 323-332.

$134 \quad$ Journal of Information \& Systems Management Volume 8 Number 4 December 2018

